\title{
On Strategic Orientation of Student Educational Activity
}

\author{
Boris E. Fishman ${ }^{1, *}$, Bogdana S. Kuzmina ${ }^{2}$, Olga A. Fokina ${ }^{3}$, Natalia G. Bogachenko ${ }^{4}$, Natalia B. Moskvina ${ }^{5}$, and \\ Svetlana P. Mashovetz ${ }^{6}$ \\ ${ }^{1}$ Department of Pedagogics, Sholom-Aleichem Priamursky State University, 679015, Shirokaya st., 70-a, Birobidzhan, Russia, \\ ${ }^{2}$ Department of Information Systems, Mathematics and Legal Informatics, Sholom-Aleichem Priamursky State University, \\ 679015, Shirokaya st., 70-a, Birobidzhan, Russia \\ ${ }^{3}$ Department of European and Oriental Languages, Sholom-Aleichem Priamursky State University, 679015, Shirokaya st., 70-a, \\ Birobidzhan, Russia \\ ${ }^{4}$ Faculty of Philology, History and Journalism, Sholom-Aleichem Priamursky State University, 679015, Shirokaya st., 70-a, \\ Birobidzhan, Russia \\ ${ }^{5}$ Department of Theory and Methodology of Professional Education, School of Education, Far Eastern Federal University, \\ 690090, Sukhanova St., 8, Vladivostok, Russia \\ ${ }^{6}$ Department of Theory and Methodology of Professional Education, School of Education, Far Eastern Federal University, \\ 690090, Sukhanova St., 8, Vladivostok, Russia
}

\begin{abstract}
The article deals with the research in the field of the strategic orientation of educational activities in higher education. The necessity of applying a student-centered approach in such studies is revealed. It is noted that the factors influencing the strategic orientation of the student educational activity relate either to the space of 'due' or to the space of 'being'. The invariant core of the graduate competence model belongs to the target-oriented space of the 'due'. It includes 12 clusters of competencies and describes the normative context of the strategic orientation of the student educational activity. The personal context of this orientation is formed on the basis of a variety of students' goals in the space of 'being'. It is characterized by student's ideas about the relative importance of the qualities that one will need in future after graduation. The technique of establishing a hierarchy of combined graduate qualities is described. This hierarchy is determined by the student's goals, which can be reflected through the subjective significance of the considered qualities for one. The analysis of results showed that the gender of the student and the character of his future labour activity significantly influence one's strategic orientation.
\end{abstract}

\section{Introduction}

The strategic orientation of educational activity is predominantly examined to meet diverse needs of educational institutions. Such studies are conducted at the country level, university and training group levels. For example, to optimize the recruitment and training of foreign students at universities, the education quality of the country is studied through the students' perception [1-3].

For the needs of strategic management of a university, different researches are carried out for choosing and proving a university adequate orientation, for instance, entrepreneurial universities are oriented to the market [4]; research universities are aimed at developing the fundamental science and training postgraduates [5], innovative universities are oriented to inventing new technologies and forming new markets and economic sectors [6], etc.

Special investigations are made to solve the problems of educational activity. For example, it is common for students not to complete their university studies because of racial, social, cultural, and other characteristics of their personalities that distinguish them from the university sociocultural environment. In order to reduce the risk of such situations, scientists examine various opportunities for creating an environment in which students feel possessing equal rights and being valued, and teachers overcome hidden prejudices and support students [7-8], etc.

'Freshman shock' can play an essential role. It is associated with the lack of knowledge of the higher education system, unwillingness to adapt in the academic environment, etc. To ally such shock, universities carry out special orientation programmes that are constantly being improved due to students' feedback [9-10], etc.

Various options for activating the educational process of training groups are studied:

- integration of traditional academic disciplines and research-based courses [11];

- making a room for dialogic interaction between a teacher and students in classroom response systems [12];

- usage of special electronic systems that allow students to answer questions quickly [13];

* Corresponding author: bef942@mail.ru 
- stimulating students' interests and activity in the classroom by using their own electronic devices [14], etc.

An important feature of almost all studies in the field of the strategic orientation of the educational activity is that students are considered only as objects from which necessary information is received. If the student is considered as the centre of the educational process, it is necessary to consider the factors that determine the strategy of his activity. Among them such factors as students' goal-settings, their ideas about future necessary qualities that will be important after graduation play a significant role.

Each student designs and implements an individual strategy of the educational activity in accordance with his own interpretation of the actual situation. It is how the student perceives himself now, and how he 'sees' himself in the future that determines the purpose of his strategy and the meaning that he assigns to his activities.

Factors that affect the strategic orientation of the student educational activity refer a) to the space of 'due'; b) to the space of 'being'.

The factors of the space of 'due' influence the student indirectly, that is through teachers who are guided by the current requirements for the educational activity and its results. The content of these requirements is conveyed by teachers to students in the classroom and provide them with the normative context for the strategic goal-setting.

Each student designs and implements an individual strategy in accordance with the actual situation formed by him. Besides the factors of the space of 'being', directly affecting the student, influence the personal life position context of his strategy.

The normative goals of the student educational activity are defined by Federal State Educational Standards as those results of higher education that allow working successfully in the chosen field of activity. Today, these results are described by means of a graduate competence model, namely the system of competences that should be developed.

In the structure of the graduate competence model, the invariant core can be identified [15]. It includes those competencies that provide a broad socio-professional adaptability of the graduate and change if the socioeconomic structure of the society undergoes fundamental changes.

The semantic analysis of selected competencies identified 12 macro components of the invariant core of the graduate competence model (ICGCM). They are clusters of competencies that describe the normative context of the strategic orientation of the student educational activity.

However, the personal context of this strategic orientation has not yet been defined and studied. The study described in this article was undertaken to fill this gap.

\section{Research Methods}

The strategic orientation of the educational activity of a university student is formed on the basis of the image of himself in the future, the image of himself as a graduate. The present study accepts the hypothesis that the structure of student's self-perception as a graduate is congruent to the structure of ICGCM. It means that the structure of the personal context contains 12 macro components corresponding in their meanings to those that were identified in the structure of ICGCM [15].

It is clear that the strategic orientation under consideration is defined by the hierarchical structure of students' preferences in relation to the components of the personal context. And such structure can be defined by a pairwise comparison of various components and a choice of a more significant component in each pair [16]. The criterion on the basis of which the comparison and choice are made is a subjective significance of the selfperception components in the future for the student.

However, the direct use of the descriptions of 12 macro components of ICGCM for students' pairwise comparison is inappropriate. The reason is that the content of these macro components is presented in the language' of Federal State Educational Standards, which focuses on professional educators. It is difficult for students to understand the meaning of macro components expressed in an unfamiliar language.

The 'translation' of the content of 12 macro components of ICGCM from the 'language' of Federal State Educational Standards into the 'language' of students was the first goal of this research. An iterative two-step procedure was used to solve it.

At the first step of either iteration, a group of experts (researchers in the field of professional education) formulated a semantic equivalent of the names of ICGCM macro components. The use of special and professional terms was excluded. The new names were to characterize the combined graduate qualities corresponding to 12 macro components of ICGCM.

At the second step, a randomly selected group of students interpreted in detail the content of the proposed combined qualities of the graduate. The results were given to the experts.

They could decide that the interpretation of the content meaning was not significantly different from the corresponding ICGCM macro component. In this case, it was considered that the translation into the students' 'language' was successful. But experts might decide that the interpretation of the content meaning significantly differed from the corresponding ICGCM macro component. Then the two-step iteration was again repeated, but the experts formulated new semantic equivalents of the names of ICGCM macro components.

The procedure was completed when the translation of all macro components into the 'language' of students was recognized by experts as successful.

The purpose of the second task of the study is to determine the personal context of the strategic orientation of the student educational activity. It was stated above that such context is displayed by the hierarchy of the combined qualities of the graduate. This hierarchy is determined by the subjective importance of the considered qualities for the student. To establish this 
hierarchy, a random sample of students was selected; each student made a pairwise comparison of various combined qualities of the graduate and chose a more significant quality of each pair.

The analysis of the data that reflects the results of students' choice made by them in the course of the pairwise comparison makes it possible to assess the influence of such factors as the gender of the student and the character of his future labour activity.

\section{Results and Discussion}

The first problem was being solved by:

- 5 professors of pedagogical and mathematical subjects as experts;

- 49 students of the second and third years of study as interpreters of the content of the combined qualities of the graduate; they were randomly selected at the Faculty of Pedagogy and Psychology - the Centre for Pedagogical Education.

As results there were the following combined qualities of the graduate corresponding to 12 macro components of ICGCM.

1. Ability to interact.

2. Social responsibility.

3. Legal literacy.

4. Ability to maintain health.

5. Ability to axiological orientation in the world.

6. Ability to use the Russian language for communication.

7. Ability to use a foreign language for communication.

8. Working knowledge of information technologies.

9. Ability to carry out cognitive activities.

10. Ability to carry out daily routine activities.

11. Ability to self-improvement.

12. Ability to provide protection against the consequences of accidents and natural disasters.

To solve the second problem, there was prepared a special questionnaire to do a survey of students. Each respondent was asked to compare in pairs different qualities of a graduate and to choose in each pair a quality, which he considers more significant, more important.

A total of 127 randomly selected students participated in the survey, including 49 young men and 78 young women. Figure 1 presents a histogram of the frequency distribution of choosing the combined graduate qualities by male students and female students. This figure shows that there is a lot in common between these distributions. This is also evidenced by the value of the correlation coefficient $r_{\text {cor }}=0.752$.

Using the criterion $\chi^{2}$, it was determined whether there are statistically significant differences between the frequency distributions of choosing the combined graduate qualities by male students and female students. The hypothesis about the absence of statistically significant differences between these distributions was considered. It was found that $\chi^{2}=26.293$. For 11 degrees of freedom and $\alpha=0.05$ critical value $\chi_{c r}^{2}=19.675$, that is $\chi^{2}>\chi_{c r}^{2}$. It means that the hypothesis under consideration must be rejected, that is, there are statistically significant differences between the concerned distributions.

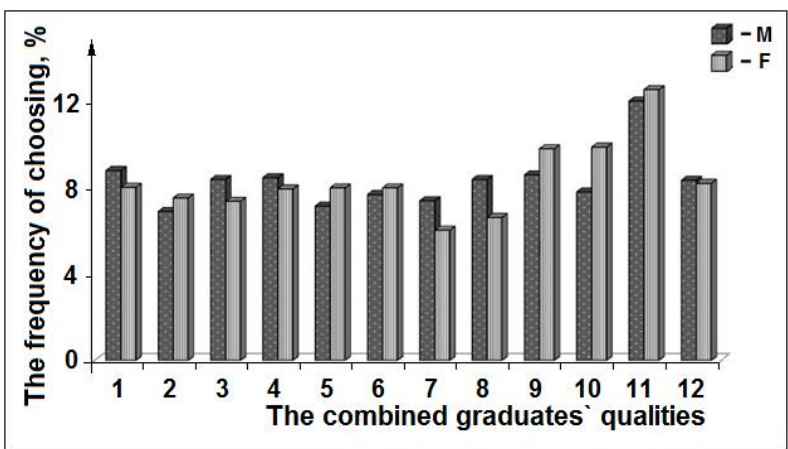

Fig. 1. Histogram of the frequency distribution of choosing the most important combined graduate qualities by each male student (M) and female student (F). The horizontal axis shows the numbers of university graduates' qualities; the vertical axis shows the frequency of choosing (in percentage).

A detailed analysis showed the main differences. Male students choose 'working knowledge of information technologies' (No. 8) and 'ability to use a foreign language for communication' (No. 7) more often than female students. At the same time, female students choose 'ability to carry out daily routine activities' (No. 10) and 'ability to carry out cognitive activities' (No. 9) more often than male students.

The available data allows finding out whether the character of the future labour activity of the student affects the structure of his self-perception as a graduate. For this reason, the data on the pairwise comparison and frequency of choosing the most important combined graduate quality were divided according students' areas of study. 12 groups of students were formed. Each group includes students who major in one of the areas of study such as:

1) Pedagogical Education;

2) Customs Affairs;

3) Psychology;

4) Journalism;

5) History;

6) Linguistics;

7) Service;

8) Law;

9) Information Systems and Technologies;

10) Power Engineering and Electrical Engineering;

11) Advertising and Public Relations;

12) Social Work.

For each of the groups, there was the frequency distribution of choosing the most important of the combined graduate qualities in a pairwise comparison of these qualities. Each distribution reflected the character of students' self-perceptions as graduates in the corresponding groups.

In order to characterize the specificity of such selfperceptions, the combined qualities that were most often chosen by students of this or that particular group were considered. Thus we applied such a rule of choosing as the necessity to be limited only to those combined 
qualities which total frequency of choosing reached value of $50 \%$ or exceeded this value. The use of this rule helped to make a conclusion that a ranked set of five most frequently selected combined qualities should be considered in each group.

It was found out that the specific structure of the selected set of the combined qualities characterizes each group of students.

Figure 2 presents the components of the selected sets of combined qualities, the most frequently chosen by students of the four areas of study. This figure shows that the graphic images of the selected sets, in fact, are cognitive maps, which help to visualize self-perception of students of the relevant groups of themselves as graduates.

The analysis of all the selected sets of combined qualities shows that there is an invariant component (IC) in all of them. In all groups of students 'Ability to selfimprovement' (№11 of 12 macro components of ICGCM) occupies the first or the second, or the third position of the ranked set of the combined graduate qualities.

The following components of the selected sets of combined qualities for each group of students were discovered.

'Pedagogical Education' Group: 1) ability to carry out cognitive activities; 2) IC; 3) ability to carry out daily routine activities; 4) working knowledge of information technology; 5) ability to interact.

'Customs Affairs' Group: 1) ability to provide protection against the consequences of accidents and natural disasters; 2) IC; 3) ability to maintain health; 4) social responsibility; 5) ability to interact.

'Psychology' Group: 1) IC; 2) ability to carry out daily routine activities; 3 ) ability to carry out cognitive activities; 4) social responsibility; 5) ability to interact.

'Journalism' Group: 1) IC; 2) ability to use the Russian language for communication; 3) social responsibility; 4) ability to carry out cognitive activities; 5) ability to interact.

'History' Group: 1) IC; 2) ability to carry out daily routine activities; 3) ability to carry out cognitive activities; 4) social responsibility; 5) ability to interact.

'Linguistics' Group: 1) IC; 2) ability to carry out cognitive activities; 3) ability to use a foreign language for communication; 4) ability to maintain health; 5) ability to provide protection against the consequences of accidents and natural disasters.

'Service' Group: 1) IC; 2) ability to carry out cognitive activities; 3 ) ability to carry out daily routine activities; 4) ability to preserve health; 5) ability to interact.

'Law' Group: 1) IC; 2) legal literacy; 3) ability to use the Russian language for communication; 4) ability to carry out cognitive activities; 5) ability to interact.

'Information Systems and Technologies' Group: 1) IC; 2) working knowledge of information technology; 3) ability to carry out daily routine activities; 4) ability to carry out cognitive activities; 5) ability to interact.

'Power Engineering and Electrical Engineering' Group: 1) ability to interact; 2) legal literacy; 3) IC; 4) ability to maintain health; 5) ability to use a foreign language for communication.

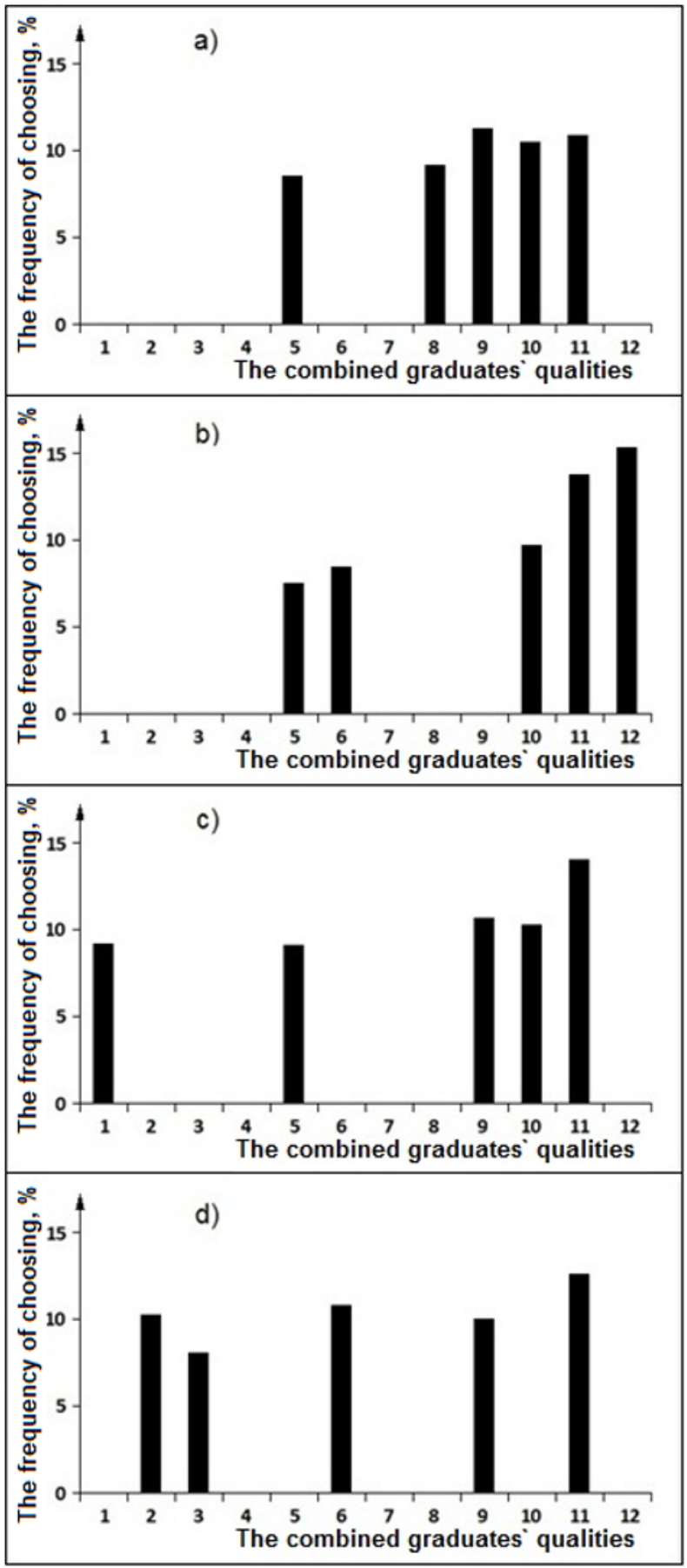

Fig. 2. Components of the selected sets of combined qualities, the most frequently chosen by students of such areas of study as a) Pedagogical Education; b) Customs Affairs; c) Psychology; d) Journalism. The horizontal axis shows the numbers of university graduates' qualities; the vertical axis shows the frequency of choosing (in percentage).

'Advertising and Public Relations' Group: 1) IC; 2) ability to maintain health; 3) ability to interact; 4) legal literacy; 5) ability to carry out daily routine activities.

'Social Work' Group: 1) IC; 2) ability to use a foreign language for communication; 3) working knowledge of information technology; 4) ability to use 
the Russian language for communication; 5) ability to interact.

First of all, we should notice that the results indicate a significant variability of how each student 'sees' himself now and how he 'sees' himself in the future. Such perception is significantly influenced by the peculiarities of educational activity, which are connected with the character of students' future labour activity. This is evidenced by the test on the criterion of $\chi^{2}$, which shows that the distribution of combined qualities, the most frequently chosen by students of different areas of study, statistically significantly differ.

Another factor that affects the student's understanding of the meaning of his/her educational situation to a certain extent is the gender of the student.

However, all results require verification and refinement, because they are not obtained from a very large sampling of students. The total number of respondents was 127 people (49 male students and 78 female students), and the number of students of different areas of study varied from 10 to 12 people.

\section{Conclusion}

It should be noted that such combined qualities of the graduate as 'ability to self-improvement', 'ability to carry out cognitive activity' and 'ability to carry out daily routine activity' received the highest rating among all respondents. In our opinion, it indicates the fact that the majority of students are aware of the importance of their personal activity for building their successful future career.

The personal context of the strategic orientation of the student educational activity is displayed in the selfimage as a graduate. Each student has this image, but he is not always aware of it in detail. For its 'manifestation' it is necessary to make pairwise comparisons of various combined qualities of the graduate and choose a more significant quality in each pair. As a result, the selfimage as a graduate is determined by each student in the field of the combined qualities under consideration. It should be noted that the results characterize the personal context of the strategic orientation of the student at the time of the survey.

How stable is such a personal context? To answer this question, it is necessary to conduct further studies using the same method. If it turns out that there are certain changes in the personal context, then the task will be to determine the conditions that ensure the preservation of this context or its change in the right direction. If we find out that the personal context is stable, then it will be necessary to study when it is formed and what affects the process of its formation.

For higher education, it is important to compare how students represent themselves as graduates with the expectations that employers have. If the ranking of combined qualities that characterize the expectations of employers corresponds to the ranking of the same qualities in the representation of students, then we can say about a good 'setup" of higher education for employers' requests. However, there are various claims of employers about the qualities of graduates. Hence, it is quite possible that the ranking of combined qualities obtained from employers does not correspond to the ranking of the same qualities in the representation of students. Examining such essential differences will allow universities to improve their educational process.

The article is done as a part of state task 27.5905.2017 / 8.9 'System-cognitive approach to recognition of individual academic strategies of university students on the basis of dynamics of their academic success and characteristics of emotional burnout' (2017 - 2019).

\section{References}

1. M. Russell, International Journal of Contemporary Hospitality Management 17 (1), 65-77, (2006)

2. R. Voss, T. Gruber, \& I. Szmigin, Journal of Business Research 60 (9), 949-959, (2007)

3. D.J. Beaumont, Service quality in higher education: the students' viewpoint. A dissertation submitted to the University of Manchester for the degree of Bachelor of Science in the Faculty of Humanities, (2012)

4. P. Schulte, Higher education in Europe 29, 187-193, (2004)

5. The Carnegie Classification of Institutions of Higher Education. A technical report with a foreword by Lee S. Shulman. Carnegie Publications, (2001)

6. Reuters Top 100: The World's Most Innovative Universities $\quad-\quad 2017$.

URL: https://www.reuters.com/article/us-amersreuters-ranking-innovative-univ/reuters-top-100-theworlds-most-innovative-universities-2017idUSKCN1C209R, (date of access: 19.04.18)

7. T. L. Killpack, L. C. Melón, Life sciences education 15(3) (2016)

8. P. G. Devine, P. S. Forscher, A. J. Austin, W. T. L. Cox, Journal of Experimental Social Psychology, 48, 1267-1278, (2012)

9. J. M. Davis, The impact of orientation programming on student success outcomes at a rural community college. Online theses and dissertations, (2013) URL: https://encompass.eku.edu/etd/160, (date of access: 14.04.18).

10. H. D. Ali, International Journal of Innovative Studies in Sociology and Humanities 2(6), 18-24 (2017)

11. Healey, M. \& Jenkins, A. Strategies for developing an active research curriculum, (2010). URL: https://cndls.georgetown.edu/media/document s/recentevents/active-research-curriculum.pdf, (date of access: 01.04.18).

12. C. Fies \& J. Marshall, Journal of Science Education and Technology 17 (5), 483-499 (2008)

13. U. Cakiroglu, F. Erdogdu, S. Gokoglu, 9(2), 171185 (2018) 
14. M. Wijtmans, L. van Rens \& J. E. van MuijlwijkKoezen, Journal of Chemical Education 91(11), 1830-1837 (2014)

15. B.E. Fishman, B.S. Kuzmina, I.L. Pitsuk, Modern Problems of Science and Education 4 (2017)

16. N.B. Moskvina, Higher Education in Russia 7, 8693 (2016) 